\title{
A BIM-BASED IDENTIFICATION AND CLASSIFICATION METHOD OF ENVIRONMENTAL RISKS IN THE DESIGN OF BEIJING SUBWAY
}

\author{
Mingke ZHOU® ${ }^{*}$, Yuegang $\mathrm{TANG}^{1}$, Huai $\mathrm{JIN}^{1,2}$, Bo ZHANG ${ }^{2}$, Xuewen $\mathrm{SANG}^{2}$ \\ ${ }^{1}$ College of Geoscience and Surveying Engineering, China University of Mining \& Technology, Beijing, China \\ ${ }^{2}$ Beijing Rail and Transit Design \& Research Institute Co. Ltd., Beijing, China
}

Received 26 June 2020; accepted 1 June 2021

\begin{abstract}
The subway project safety risk management in China covers design and construction stages. The traditional method for identifying construction safety risks at the design stage requires that engineers work backward, and it relies on engineers having an accurate understanding of complex engineering information, spatial relationships, and rich experience. This paper proposes a Building Information Modeling (BIM) based automatic identification and classification framework for environmental risks at the subway design stage. First, a database of discriminant rules was established in order to achieve the digital expression of the discriminant standards for environmental risks. Second, environmental models and discriminant models were created in order to analyze spatial collisions. Then, the risk discrimination algorithm was embedded in the BIM platform. The program automatically analyzed the collision result-based discrimination rule database and output a list of environmental risks associated with the model. Finally, a shield tunnel was used for practice. As a result, the BIM-based method for automatically identifying environmental risks could improve the efficiency of the special design of safety risks and promote the digital transmission of risk design information throughout the construction process. The method described in this paper provides a reference for the safety risk management technology system in China's subway projects. This method can also be applied to projects such as underground pipe gallery, power tunnel, and foundation pit, after optimizing the classification rules.
\end{abstract}

Keywords: BIM, environmental risk, risk grade, rule base, discriminant algorithm, subway project, BIM platform.

\section{Introduction}

The safety risks associated with subway projects are particularly serious given the complexity of subway project construction (Yu et al., 2014). Subway construction may adversely affect the safety of the facilities in the surrounding environment, such as buildings and underground pipelines. However, the surrounding environment restricts the construction conditions and exacerbates the construction risks associated with subway (Jin et al., 2011). China's subways have entered a period of rapid construction in recent years, with more than 40 cities implementing subway projects. The lack of management experience has led to frequent accidents (Zhou et al., 2013; Tam et al., 2004). The safety risks associated with construction projects have been gradually increasing with the complexity and scale of those projects. Therefore, identifying, assessing, and then eliminating or avoiding risks at an early stage is important for risk management.
The Ministry of Housing and Urban-Rural Development of China has formulated risk-management norms for underground subway projects, clarifying the engineering risk grade standards and risk management measures at different stages of construction (Zhang et al., 2012) in order to provide a guide for cities undertaking subway projects and encourage cities to establish a safety risk management system. Cities such as Beijing, Shanghai, and Guangzhou, based on their own particular characteristics, have established a multi-unit collaborative safety risk management system, including risk grading rules (Wu et al., 2012), assessment methods, and monitoring requirements. These cities adopted the same principle of avoiding major risks at the design stage, assessing risks before the start of construction, and applying key control during construction. Additionally, a two-dimensional geographic information science (2DGIS)-based risk manage-

*Corresponding author. E-mail: 583281417@qq.com

Copyright $\odot 2021$ The Author(s). Published by Vilnius Gediminas Technical University

This is an Open Access article distributed under the terms of the Creative Commons Attribution License (http://creativecommons.org/licenses/by/4.0/), which permits unrestricted use, distribution, and reproduction in any medium, provided the original author and source are credited. 
ment and control information system was developed as a management and control tool (Ding et al., 2012, 2013). This mature working model has been widely adopted by other cities, greatly improving the safety risk management of their rail transit construction.

Accurately assessing the environmental safety risks caused by subway construction in the design phase (Jin et al., 2011), and adopting reliable design schemes and environmental protection measures are very important in reducing the occurrence and consequences of safety risks. The particular issue of environmental risk identification and classification for subway construction includes formulating risk evaluation standards and obtaining major parameters such as importance of environmental facility and closeness. Researchers have studied the use of BIM to identify and mitigate possible personal safety accidents on site. The BIM-based method of environmental risk identification of subway has not yet been studied. Beijing has promoted the Safety Risk Assessment Specification of Beijing, which provides 44 risk grading diagrams for 11 categories environmental objects using four different construction methods. The environmental risk identification for a subway line always involves all types of construction methods and environmental objects. The adoption of risk grading diagrams and the identification of closeness between the project and the surrounding environment are complicated, which makes risk identification difficult and inefficient.

Safety risk management based on traditional technologies such as 2D GIS and computer aided design (CAD) has reached a bottleneck. The efficient management of risk information has been realized, but problems that affect the pre-order work, such as the unintuitive expression of engineering information, difficulty in identifying safety risks, and inaccurate judgment, have not yet been solved. Therefore, there is an urgent need to adopt more efficient and intelligent technical means of risk identification, grading, assessment, and management. The rapid development of visual technologies such as building information modeling (BIM) and 3D GIS has given rise to new solutions for the construction of digital subways (Zhou et al., 2017, 2019; Tam et al., 2004) by providing a new management method while guaranteeing the efficient exchange of information (Dossick \& Neff, 2011).

This study systematically presents a BIM-based automatic method for environmental risk classification at the design stage of a subway project in Beijing. Figure 1 shows the research framework for the steps taken in the research plan. The discriminant rules are established and stored as a database table by refining the 44 risk grading diagrams and re-partitioning coding. On this basis, the requirements for modeling, automatic discriminating algorithm, and BIM platform development are proposed. Finally, a shield tunnel is used for practice. Consequently, it is observed that the BIM-based method for automatically identifying environmental risks could improve the efficiency of the special design of safety risks and promote the

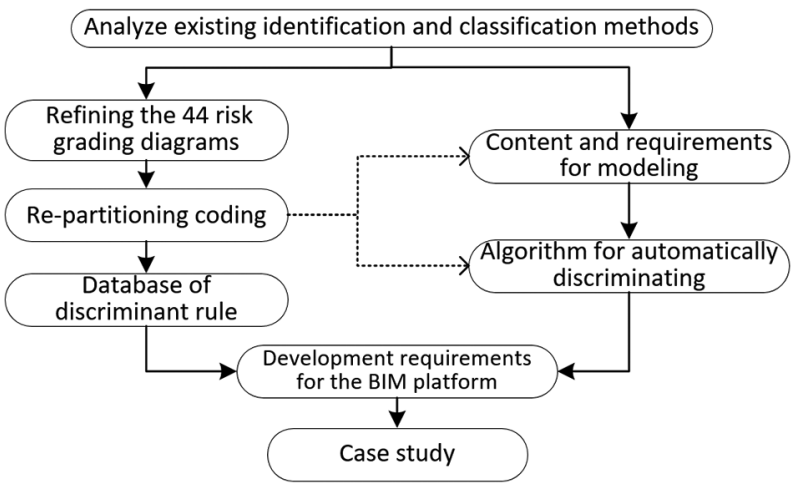

Figure 1. Research framework

digital transmission of risk design information throughout the construction process. The method described in this paper provides a reference for the safety risk management technology system in China's subway projects. Moreover, this method can also be applied to projects such as underground pipe gallery, power tunnel, and foundation pit, after optimizing the classification rules.

\section{Literature review}

\subsection{Safety risk management system for a subway project in China}

Subway safety risks include engineering risks and environmental risks (Beijing Municipal Commission of Housing and Urban-Rural Development, 2014). Engineering risk refers to how the safety of a structure will be affected or how a risk event will occur due to the characteristics of the structure, the complexity of the geology, or the construction. Environmental risk refers to environmental objects such as buildings, pipelines, and bridges, which may be affected or destroyed due to project construction. Safety risks for underground construction are related to many influential factors such as underground architectural forms, construction techniques, geological hydrogeological conditions, and surrounding environments ( $\mathrm{Li}$ et al., 2018a). In the primary stage, safety risk management mainly focuses on construction deformation monitoring and the information management of monitoring data (Yang et al., 2004).

However, China's subway construction is developing rapidly, and engineering construction safety accidents occur frequently. Researchers have studied the safety risk management system in the entire process of engineering construction. Luo et al. (2007) proposed risk assessment methods, content, and corresponding protection measures for the impact of subway construction on neighboring buildings. Jin et al. (2008) studied the principles and processes for establishing a safety risk system and proposed the main content and processes of safety risk management in 10 key stages. Wang et al. (2009) proposed a framework for risk management during the construction of subway tunnels, including risk identification, analysis and evalua- 
tion, response, and risk prevention measures. Luo (2009) proposed a multi-party safety risk management system and a supporting safety risk management and control system. According to the location relationship between the building and the tunnel, Wu et al. (2011) divided the safety levels of neighboring buildings, and classified and evaluated the safety risk levels of the buildings. Wu et al. (2012) then proposed that the risk grade of the surrounding environment can be divided according to the closeness between the project and the surrounding environment (spatial location relationship) as well as the importance of the surrounding environment. He divided the importance into four levels and gave examples.

After years of development, the theory and technology system of safety risk management for subway engineering has been formed in China. The risk management framework is shown in Figure 2 (Beijing Municipal Commission of Housing and Urban-Rural Development, 2014). At the design stage, the engineering risks and environmental risks are identified. Then, theoretical analysis, numerical simulation, and other methods are used to analyze and evaluate risks. Finally, risk control measures are designed, such as avoiding irrelevant factors and protecting the environment, and then risk monitoring programs are proposed. In the construction stage, identifying risk factors, monitoring of risk, and eliminating risk events are carried out to realize the dynamic management of safety risks. Ideally, most of the foreseeable risks should be "designed out" at the planning or design stages, and the residual risks should be managed during the construction and subsequent phases (Zou et al., 2007).

According to the environmental importance and closeness standards followed by Beijing, the environmental risk levels was divided into four grades and the closeness was defined according to different construction methods as shown in Table 2 (Beijing Municipal Commission of Housing and Urban-Rural Development, 2014). This paper refines the graphical representation of the closeness and integrates the original 44 risk grading diagrams into four, finally establishing the discriminant rule base for the automatic identification of environmental risks.

\subsection{Development of building information model technology}

BIM assists engineers and managers by enabling collaborative design and construction simulation (Jin et al., 2017), offering the advantages of $3 \mathrm{D}$ visualization and information integration. As such, it has been widely used in engineering. BIM can streamline processes and promote lean construction (Sacks et al., 2010). It also plays a major role in the management of facilities and equipment during construction operations (Becerik-Gerber et al., 2012). BIM is increasingly being used as a reliable method for sustainable construction practices (Santos et al., 2019).

With increases in automation, intelligent demand, and the rapid development of information technology such as GIS and the Internet of Things (IoT), engineers are paying more attention to the integration and application of BIM and information technology, and extensive technical research has been carried out in this area. For example, automatic drawing review is possible by extracting key design parameters from a model (Luo \& Gong, 2015). BIM is also used to organize and manage quality acceptance information (Ma \& Mao, 2015) using an algorithm that automatically generates checkpoints. It is possible to determine whether a product is qualified according to information about the materials and construction process, and to efficiently manage construction quality (Chen \& Luo, 2014). The automatic decomposition of a working module is possible by parsing the model component class and topology relationship to improve the efficiency of subcontracting in engineering projects (Isaac et al., 2017). Materials can be distributed dynamically according to engineering information and a schedule (Yu et al., 2016). The collaborative management of engineering projects is also possible when using a BIM-based platform (Park et al., 2017; Song et al., 2019). Use of BIM also helps to study how pollen exposure, influenced by weather parameters, can be assessed and integrated in the designing and building of constructions as other component of air quality assessment beforehand (Fernández-Rodríguez et al., 2018). The integrated platform based on BIM and GIS can facili-

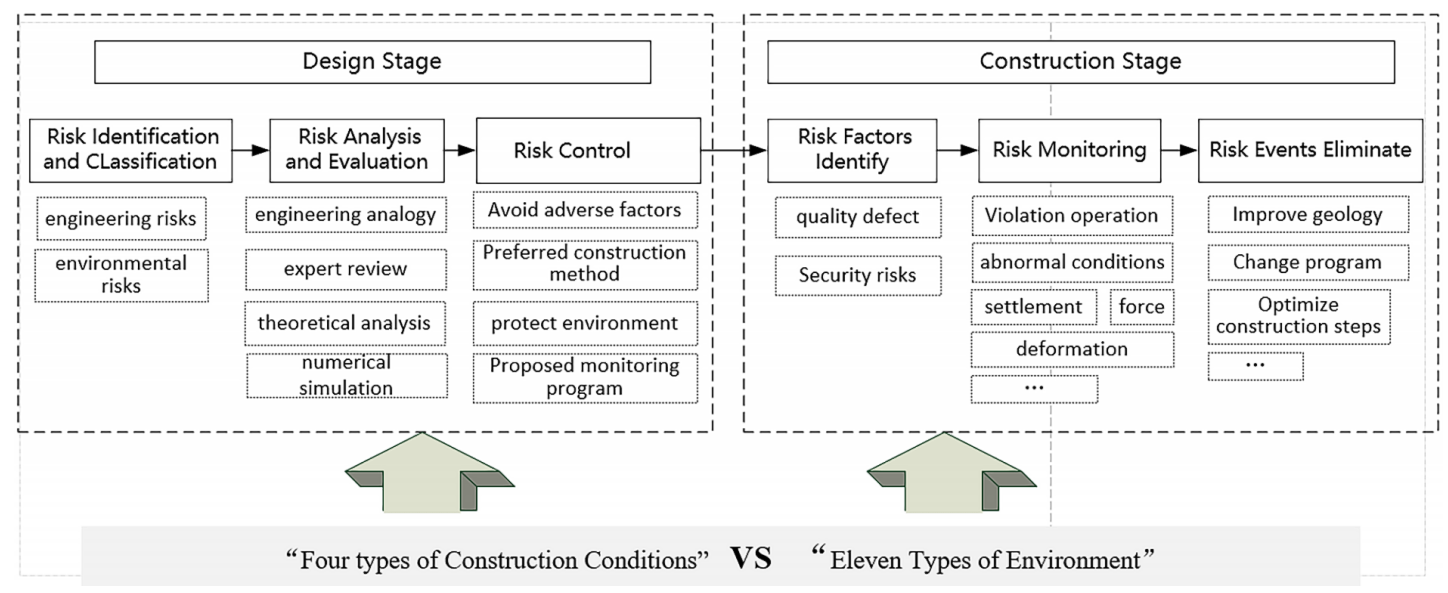

Figure 2. Framework of the safety risk management system for a subway project in China 
tate utility management in many aspects, such as the condition assessment, decision support, and utility visualization (Wang et al. 2019a, 2019b). The Unity game engine is used to integrate data, from the original BIM models and the as-built images, to achieve an automated update of the $3 \mathrm{D}$ virtual environment with states of the construction site (Rahimian et al., 2019).

BIM technology has been used in all aspects of construction progress, quality, contracts, and safety management, and it continuously changes the construction management mode of projects through information collaboration. The "BIM-based construction management system" was rated as being in the top ten innovations in the field of engineering management by the Chinese Academy of Engineering (2018).

\subsection{Application of BIM in safety risk management}

BIM-based risk management has become a new trend (Zou et al., 2017). Researchers have conducted extensive research addressing engineering safety risk management issues. BIM-based risk management includes three aspects, identification and mitigation of these risks in design, the intelligent management of site safety, and risk prediction at the pre-construction stage.

The design stage is the best opportunity to mitigate most of these risks if potential hazards could be well identified and given reasonable protective measures, and corresponding measures to control these risks can be chosen correctly (Bansal, 2011). Malekitabar et al. (2016) proposed five sets of safety risk drivers detectable during the design phase that can influence either the probability or the consequences of an accident, the application of which helped identify more than $40 \%$ of potential fatalities in construction projects. Tang et al. (2021) developed a safety evacuation design toolbox (SEDT) based on the BIM platform to propose strategies for optimizing the station design and improve emergency evacuation safety. Lu et al. (2021) developed a plug-in in Autodesk Revit that links BIM with safety risk data, which can automatically calculate construction safety risk to help architects and structural designers quickly select design alternatives while reducing occupational injuries and fatalities at the construction stage.

The management of site safety mainly involves technologies such as the Internet of Things (IoT) and image recognition for monitoring and analyzing construction behavior and safety statuses. Dong et al. (2018) proposed a method for managing the behavior of works by monitoring a worker's behavior through positioning and IoT technology and displaying the position and safety status in a model. Qu (2017) proposed that safety risks such as mechanical strikes and falls from heights could be addressed by simulating construction machinery and safe, well-ordered construction sites. Zhou et al. (2013) proposed a
$4 \mathrm{D}$ platform for integrating and analyzing construction operation information to determine whether there were violations such as over-excavations or support failures. In order to strengthen the safety level of construction facilities, Kim et al. (2018) used BIM software to optimize a scaffolding scheme while considering safety, rationality, and cost factors. Sloot et al. (2019) used 4D BIM tools to support the development of highly effective risk mitigation strategies, such as evaluating various design and process alternatives, given a specific constraint.

Scholars have carried out the following research about risk prediction at the pre-construction stage. Ding and Zhou (2013) developed a web-based system to provide a safety risk assessment and early warnings automatically during construction based on multisource information (monitoring measurements, calculated predictions, and visual inspections). Zhang et al. (2016) presented an innovative approach for integrating BIM and expert systems to address deficiencies in traditional safety risk identification process in tunnel construction. Li et al. (2018a) established a mechanism that could achieve timely and accurate recognition at the pre-construction stage in order to identify possible risks automatically based on design parameters and geological data, and to then give recommended measures. Li et al. (2018b) presented the Safety Risk Identification System (SRIS) and Early Warning System (SREWS) for China's subway construction at the pre-construction stage. Hossain et al. (2018) presented a structured Design-for-safety (DfS) rule-based knowledge library to provide safety knowledge and proposed an intelligent BIM-integrated risk review system to assist designers in accounting for construction-related hazards during their design. Zhou et al. (2019) proposed an intelligent model based on a random forest (RF) that was established for the risk prediction of deep foundation pits in subway stations. Based on the hierarchy of factors that influence subway station construction risk, Shen et al. (2019) proposed a model of three-stage fuzzy synthetic evaluation to rank risks during construction.

In summary, the existing BIM-based risk management research is mainly concentrated in three stages. To prevent any human safety accidents on site, BIM is used to identify and mitigate these risks in design. Before the construction starts, BIM can be used to predict risks such as mechanical strikes, falls from heights, and structural collapse to give recommended measures. Construction behavior and safety status is then monitored to provide a risk assessment and early warnings during the construction phase.

This paper innovatively proposes a BIM-based automatic identification and classification method for environmental risks at the design stage, which has not been adopted in any previous similar studies. This method therefore will greatly improve the quality and efficiency of a designer's special design work on safety risk. This is of great significance to the entire process of safety risk management. 


\section{Establishment of the database of discriminatory rules}

\subsection{Safety risk rating criteria}

The "Beijing Rail Transit Safety Risk Management System" has detailed requirements for risk management at the design stage as well as the construction stage. The main challenge involves identifying the risks in a project itself as well as environmental risks (Beijing Municipal Commission of Housing and Urban-Rural Development, 2014), and then implementing an appropriate design for special and grade-1 risk projects, ultimately determining the monitoring plan. Safety risks can be managed dynamically in the construction stage by implementing patrols and conducting monitoring during construction.

The rules for distinguishing between the risks in a project itself and the environmental risks are clarified in the Safety Risk Assessment Specification of Beijing. The risks associated with a project are determined by the excavation depth, section size, tunnel clearance, station layer number, and similar indicators, and the risks are corrected according to the geological conditions, group hole effects, and other factors. The environmental risk is determined by the importance of the surrounding environmental facilities and their distance from a subway structure. The environmental risk is corrected according to the geological environment and the proximity relationship (as shown in Tables 1 and 2).

The grade of a risk should be corrected in two special cases (Beijing Municipal Commission of Housing and Urban-Rural Development, 2014) after the construction drawing design is completed, to strengthen the risk management during the construction. In Case 1, a risk is upgraded by one when the geological conditions are complex, or when the environmental facilities are less secure. In Case 2, a risk is downgraded by one when shield construction is adopted or when measures have been implemented for environmental facilities during construction

Table 1. Rating of environmental safety risks

\begin{tabular}{|l|c|c|c|c|}
\hline \multirow{2}{*}{$\begin{array}{c}\text { Importance of } \\
\text { environmental } \\
\text { facility }\end{array}$} & \multicolumn{4}{|c|}{ Closeness } \\
\cline { 2 - 5 } Most important & $\begin{array}{c}\text { Closer } \\
\text { Special } \\
\text { grade }\end{array}$ & $\begin{array}{c}\text { Special } \\
\text { grade }\end{array}$ & Grade 1 & Grade 3 \\
\hline Important & Grade 1 & Grade 1 & Grade 2 & Grade 3 \\
\hline Less important & Grade 2 & Grade 2 & Grade 3 & - \\
\hline General & Grade 3 & Grade 3 & - & - \\
\hline
\end{tabular}

in order to deal with the situation of the environmental facilities having to be crossed.

Given that the degree of risk of an engineering work is derived from the main design parameters, a designer can quickly determine the risk grade while drawing up a design. The discriminative index of the risk grade of an environmental facility is mainly derived from a comprehensive analysis of external information, and as a result, the process is relatively complicated. Therefore, this paper focuses on the identification of the environmental risk grade.

\subsection{Graphical expression of discriminant rules}

A risk will differ depending on the orientation of the environmental facilities relative to new rail transit, even though the environmental facilities may be at the same distance. Moreover, because the indicators of risk level correction are not quantified, an engineer's decision relies on intuition gained from knowledge and experience (Shim et al., 2012), which introduces uncertainty into the risk level discrimination work.

Therefore, Beijing Rail Transit Construction Management Co., Ltd., which is responsible for $80 \%$ of the rail transit construction management in Beijing, has implemented a means of standardizing risk grade discrimination by refining the evaluation rules, with the ultimate goal of replacing the risk grade correction work. Ultimately, this would reduce or even eliminate the subjective intervention of a designer and thus ensure the uniqueness of risk grade determination. Based on the experience gained from more than ten rail transit construction projects in Beijing, a clear environmental risk grading method has been proposed for different levels of environmental importance and the closeness of environmental facilities and subway projects. It also provides 44 working condition and risk grading diagrams for 11 categories and 21 environmental objects using four different construction methods, as listed in Table 3. According to another research subject supported by the Beijing Key R\&D Program of China, the 44 risk grading diagrams have been recognized by experts and applied to all rail transit lines and similar projects in Beijing.

Each risk grading diagram divides a construction-affected area according to the distance relationship, clarifies the risk grade of each division, and stipulates the technical measures to be implemented in different areas. This makes the selection of the risk level determination and treatment measures at the design stage more scientific.

Table 2. Discrimination of closeness for environmental facilities and subway project

\begin{tabular}{|l|l|l|l|}
\hline \multirow{2}{*}{$\begin{array}{c}\text { Construction } \\
\text { Method }\end{array}$} & \multicolumn{3}{|c|}{ Closeness (D - Tunnel diameter) } \\
\cline { 2 - 4 } & \multicolumn{1}{|c|}{ Closer } & \multicolumn{1}{|c|}{ Close } & \multicolumn{1}{c|}{ Less close } \\
\hline $\begin{array}{l}\text { Shield } \\
\text { Construction }\end{array}$ & $\begin{array}{l}\text { Within 0.5 D above the tunnel, } \\
\text { within 0.3 D outside the tunnel }\end{array}$ & $\begin{array}{l}\text { Within 0.5-1.0 D above the tunnel, } \\
\text { within 0.3-0.7 D outside the tunnel }\end{array}$ & $\begin{array}{l}\text { Within 1.0 D above the tunnel, } \\
\text { within 0.7-1.0 D outside the tunnel }\end{array}$ \\
\hline
\end{tabular}


Table 3. Environmental risk conditions caused by subway construction

\begin{tabular}{|c|c|c|c|c|c|}
\hline \multirow{3}{*}{ Environmental facilities } & \multirow{3}{*}{ Importance } & \multicolumn{2}{|c|}{ Tunnel } & \multicolumn{2}{|c|}{ Station } \\
\hline & & Shield & Mining & Mining & Open-cut \\
\hline & & 01 & 02 & 03 & 04 \\
\hline Subway, railway & $\begin{array}{l}\text { Most } \\
\text { important }\end{array}$ & $\begin{array}{c}\text { Working } \\
\text { condition }(1,1)\end{array}$ & $\begin{array}{c}\text { Working } \\
\text { condition }(2,1)\end{array}$ & $\begin{array}{c}\text { Working } \\
\text { condition }(3,1)\end{array}$ & $\begin{array}{c}\text { Working } \\
\text { condition }(4,1)\end{array}$ \\
\hline $\begin{array}{l}\text { Subsidiary structures of subway and } \\
\text { railway lines, foundation of a bridge, } \\
\text { urban road, foundation of } 110-\mathrm{kV} \\
\text { high-voltage line }\end{array}$ & Important & $\begin{array}{c}\text { Working } \\
\text { condition }(1,2)\end{array}$ & $\begin{array}{c}\text { Working } \\
\text { condition }(2,2)\end{array}$ & $\begin{array}{c}\text { Working } \\
\text { condition }(3,2)\end{array}$ & $\begin{array}{c}\text { Working } \\
\text { condition }(4,2)\end{array}$ \\
\hline Residential, protected cultural relics & Important & $\begin{array}{c}\text { Working } \\
\text { condition }(1,3)\end{array}$ & $\begin{array}{c}\text { Working } \\
\text { condition }(2,3)\end{array}$ & $\begin{array}{c}\text { Working } \\
\text { condition }(3,3)\end{array}$ & $\begin{array}{c}\text { Working } \\
\text { condition }(4,3)\end{array}$ \\
\hline Underpass, overpass & $\begin{array}{l}\text { Less } \\
\text { important }\end{array}$ & $\begin{array}{c}\text { Working } \\
\text { condition }(1,4)\end{array}$ & $\begin{array}{c}\text { Working } \\
\text { condition }(2,4)\end{array}$ & $\begin{array}{c}\text { Working } \\
\text { condition }(3,4)\end{array}$ & $\begin{array}{c}\text { Working } \\
\text { condition }(4,4)\end{array}$ \\
\hline $\begin{array}{l}\text { Gas pipeline with medium or high } \\
\text { pressure, heat pipeline }(D \geq 400 \mathrm{~mm}) \text {, } \\
\text { water supply pipeline }(D \geq 600 \mathrm{~mm})\end{array}$ & Important & $\begin{array}{c}\text { Working } \\
\text { condition }(1,5)\end{array}$ & $\begin{array}{c}\text { Working } \\
\text { condition }(2,5)\end{array}$ & $\begin{array}{c}\text { Working } \\
\text { condition }(3,5)\end{array}$ & $\begin{array}{c}\text { Working } \\
\text { condition }(4,5)\end{array}$ \\
\hline $\begin{array}{l}\text { Low pressure gas pipeline; heat pipeline } \\
\text { (D } \leq 400 \mathrm{~mm}) \text {; water supply pipeline } \\
(300 \mathrm{~mm} \leq \mathrm{D}<600 \mathrm{~mm})\end{array}$ & $\begin{array}{l}\text { Less } \\
\text { important }\end{array}$ & $\begin{array}{c}\text { Working } \\
\text { condition }(1,6)\end{array}$ & $\begin{array}{c}\text { Working } \\
\text { condition }(2,6)\end{array}$ & $\begin{array}{c}\text { Working } \\
\text { condition }(3,6)\end{array}$ & $\begin{array}{c}\text { Working } \\
\text { condition }(4,6)\end{array}$ \\
\hline Power trench and heat trench & Important & $\begin{array}{c}\text { Working } \\
\text { condition }(1,7)\end{array}$ & $\begin{array}{c}\text { Working } \\
\text { condition }(2,7)\end{array}$ & $\begin{array}{c}\text { Working } \\
\text { condition }(3,7)\end{array}$ & $\begin{array}{c}\text { Working } \\
\text { condition }(4,7)\end{array}$ \\
\hline $\begin{array}{l}\text { Sewer pipe (diameter or width } \\
\geq 600 \mathrm{~mm} \text { ) }\end{array}$ & $\begin{array}{l}\text { Less } \\
\text { important }\end{array}$ & $\begin{array}{c}\text { Working } \\
\text { condition }(1,8)\end{array}$ & $\begin{array}{c}\text { Working } \\
\text { condition }(2,8)\end{array}$ & $\begin{array}{c}\text { Working } \\
\text { condition }(3,8)\end{array}$ & $\begin{array}{c}\text { Working } \\
\text { condition }(4,8)\end{array}$ \\
\hline $\begin{array}{l}\text { Rainwater pipeline (diameter or width } \\
\geq 600 \mathrm{~mm} \text { ) }\end{array}$ & Important & $\begin{array}{c}\text { Working } \\
\text { condition }(1,9)\end{array}$ & $\begin{array}{c}\text { Working } \\
\text { condition }(2,9)\end{array}$ & $\begin{array}{c}\text { Working } \\
\text { condition }(3,9)\end{array}$ & $\begin{array}{c}\text { Working } \\
\text { condition }(4,9)\end{array}$ \\
\hline $\begin{array}{l}\text { Sewer pipeline (diameter or width } \\
<600 \mathrm{~mm} \text { ) }\end{array}$ & \multirow{2}{*}{$\begin{array}{l}\text { Less } \\
\text { important }\end{array}$} & \multirow{2}{*}{$\begin{array}{c}\text { Working } \\
\text { condition }(1,10)\end{array}$} & \multirow{2}{*}{$\begin{array}{c}\text { Working } \\
\text { condition }(2,10)\end{array}$} & \multirow{2}{*}{$\begin{array}{c}\text { Working } \\
\text { condition }(3,10)\end{array}$} & \multirow{2}{*}{$\begin{array}{l}\text { Working } \\
\text { condition }(4,10)\end{array}$} \\
\hline $\begin{array}{l}\text { Rainwater pipeline (diameter or width } \\
<600 \mathrm{~mm} \text { ) }\end{array}$ & & & & & \\
\hline Rivers and canals & Important & $\begin{array}{c}\text { Working } \\
\text { condition }(1,11)\end{array}$ & $\begin{array}{c}\text { Working } \\
\text { condition }(2,11)\end{array}$ & $\begin{array}{c}\text { Working } \\
\text { condition }(3,11)\end{array}$ & $\begin{array}{c}\text { Working } \\
\text { condition }(4,11)\end{array}$ \\
\hline
\end{tabular}

Figure 3 shows the grading diagrams for working condition $(1,1)$ with a shield construction tunnel through subway or railway lines. Figure 4 shows the grading diagrams for working condition $(1,2)$ with a shield construction tunnel through the foundation of a bridge or a road.

In Figure 3, DA, DB, and DC represent the categories of closer, close, and less close. If an existing subway or railway line is located in any of these three areas in a tunnel, it is deemed to present a special risk. Furthermore, it will be necessary to strengthen the soil between the environmental facilities and the tunnel.

\subsection{Establishing the discriminant rule base}

More sophisticated discrimination rules provide designers with a clearer evaluation of indicators, which is of considerable help to environmental risk identification. However, this also raises new problems. One construction method in the new risk identification rules corresponds to 11 risk identification diagrams (as shown in Table 1), with every working condition being different.

First, the rules for dividing an area affected by the construction are different. For example, working condition (1, 1) has one more partition, DG, than working condition (1, 2 ), as shown in Figure 3 and Figure 4, and the DC area of working condition $(1,5)$ has more 0107 areas than working condition $(1,1)$.

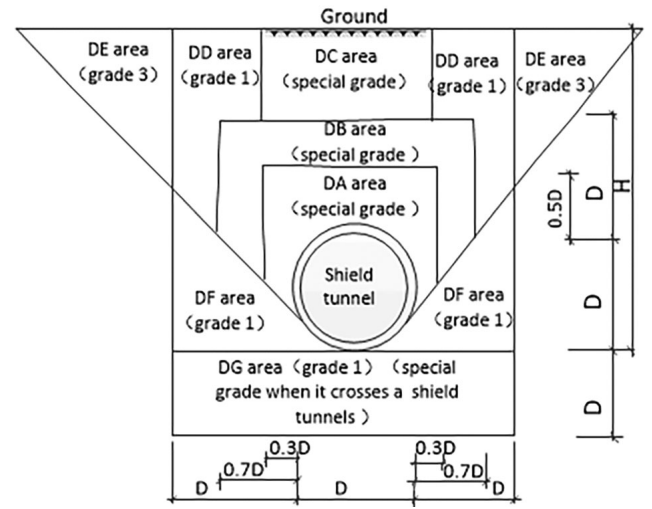

Figure 3. Grading diagram for working condition $(1,1)$

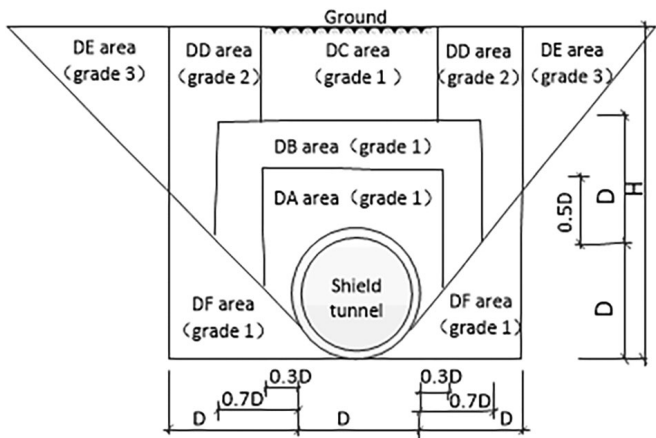

Figure 4. Grading diagram for working condition $(1,2)$ 
Second, the risk levels differ when different environmental facilities are present in an area. For example, there is a special grade risk in the DA area of working condition $(1,1)$, and a grade 1 risk in the DA area of working condition $(1,2)$.

Third, different environmental facilities may require the application of different measures even though the risk level is the same. In the case of working conditions (1, 1 ), the risk is grade one when the environmental facilities cross the DF area, and must special measures must be adopted. However, for working condition $(1,2)$, the risk has the same grade when the environmental facilities cross the $\mathrm{DF}$ area, and the decisions to implement measures are made according to the monitoring data.

Designers need to frequently switch between 44 different discriminating rules when performing risk identification. The application of more elaborate rules increases the workload while improving the design quality, which exacerbates the difficulty that is associated with determining the environmental risk grade. When an interval tunnel is a close-distance double-line tunnel, the risk discrimination work will be more complicated. Obviously, a highly parameterized discriminant rule base is necessary to promote the automatic identification of environmental risks.

A common-risk grading diagram for each of the four construction methods was produced to satisfy the dis- crimination needs of 11 environmental facilities by refining the partitioning rules and uniform encoding rules. Finally, 44 different risk classification diagrams were cxdchanged into four general diagrams according to the construction method, as shown in Figures 5-8. Taking the shield interval tunnel as an example, Figure 4 shows the addition of the 0101 area to working condition $(1,2)$ for the original partition rule shown in Table 3 and the division of the DD area of working condition $(1,2)$ into 0107 , 0108, 0109, and 0110.

The correspondence between the new partition rule number and the original partition rule letter number was analyzed, and a library of environmental risk rating rules was established based on partition coding, as shown in Table 4 . The structuring of the risk identification rules according to the rules determining the level of risk was implemented in order to facilitate risk identification based on BIM.

The rule base was expressed as $F(i, j)$. The ' $i$ ' indicates the construction method, and the ' $j$ ' indicates the environmental facilities to be crossed. $F(1,1)$ was taken as an example, corresponding to the italicized part of Table 4. A special risk was incurred when it crossed areas 0104, 0105 , and 0106 , while a grade 3 risk was incurred when it crossed areas 0111 and 0112 .

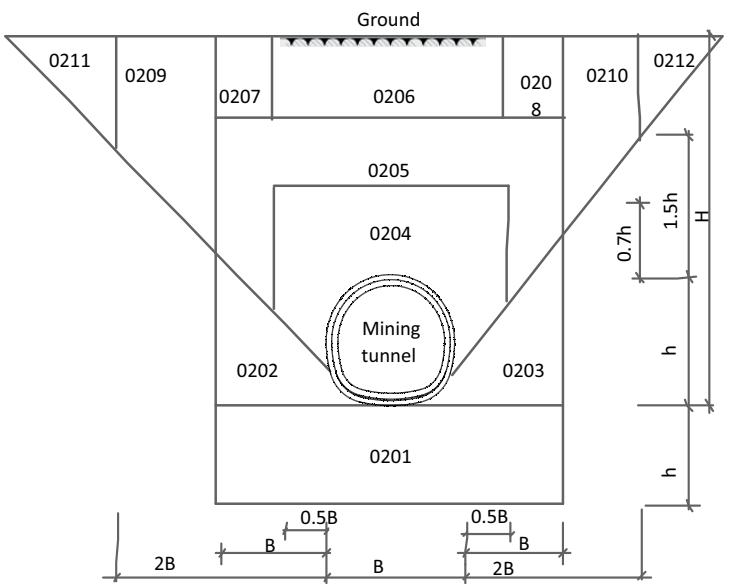

Figure 6. Mine tunnel construction

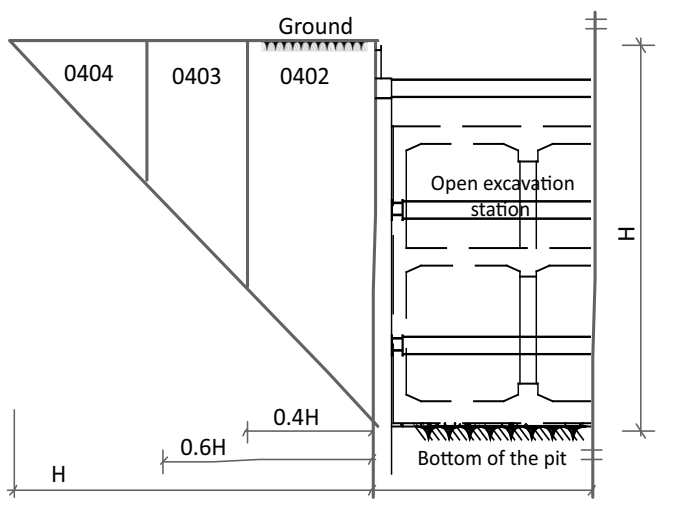

Figure 8. Open excavation station construction
Figure 7. Pile-Beam-Arch (PBA) station construction

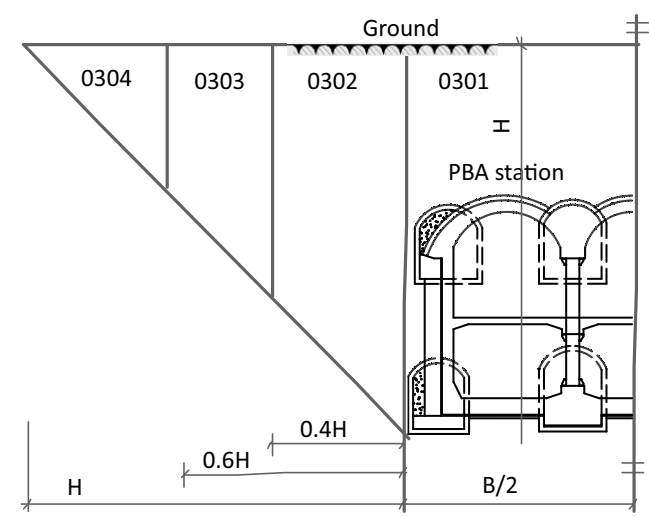


Table 4. Part of the discriminant rule base for environmental risk

\begin{tabular}{|c|c|c|c|c|c|}
\hline \multirow{2}{*}{ Environmental facilities } & \multirow{2}{*}{ Risk grade } & \multicolumn{2}{|c|}{ Tunnel } & \multicolumn{2}{|l|}{ Station } \\
\hline & & Shield & Mining & Pile-Beam-Arch & Open-cut \\
\hline \multirow{4}{*}{ Subway, Railway } & Special Grade & $0104,0105,0106$ & $0204,0205,0206$ & 0301,0302 & 0402 \\
\hline & Grade 1 & $\begin{array}{c}\text { 0101, 0102, 0103, } \\
0107,0108,0109,0110\end{array}$ & $\begin{array}{c}0201,0202,0203,0207 \\
0208,0209,0210\end{array}$ & 0303 & 0403 \\
\hline & Grade 2 & - & - & - & - \\
\hline & Grade 3 & 0111,0112 & 0211,0212 & 0304 & 0404 \\
\hline \multirow{4}{*}{$\begin{array}{l}\text { Subsidiary Structure } \\
\text { of Subway and Railway } \\
\text { Lines, } \\
\text { Foundation of Bridge, } \\
\text { Urban Road, } \\
\text { Foundation of } 110-\mathrm{kV} \\
\text { high-voltage line }\end{array}$} & Special Grade & - & - & - & - \\
\hline & Grade 1 & $0102,0103,0104,0105,0106$ & $0202,0203,0204,0205,0206$ & 0301,0302 & 0402 \\
\hline & Grade 2 & $0107,0108,0109,0110$ & $0207,0208,0209,0210$ & 0303 & 0403 \\
\hline & Grade 3 & 0111,0112 & 0211,0212 & 0304 & 0404 \\
\hline
\end{tabular}

Table 5. Database table of discriminant rules corresponding to $F(1,2)$

\begin{tabular}{|c|c|c|c|c|}
\hline $\begin{array}{c}\text { Primary } \\
\text { key }\end{array}$ & $\begin{array}{l}\text { Construction } \\
\text { method No. ' } i \text { ' }\end{array}$ & $\begin{array}{l}\text { Environment } \\
\text { type No. ' } j \text { ' }\end{array}$ & $\begin{array}{c}\text { Area } \\
\text { No. }\end{array}$ & $\begin{array}{l}\text { Risk } \\
\text { grade }\end{array}$ \\
\hline 1 & 01 & 02 & 0102 & 1 \\
\hline 2 & 01 & 02 & 0103 & 1 \\
\hline 3 & 01 & 02 & 0104 & 1 \\
\hline 4 & 01 & 02 & 0105 & 1 \\
\hline 5 & 01 & 02 & 0106 & 1 \\
\hline 6 & 01 & 02 & 0107 & 2 \\
\hline 7 & 01 & 02 & 0108 & 2 \\
\hline 8 & 01 & 02 & 0109 & 2 \\
\hline 9 & 01 & 02 & 0110 & 2 \\
\hline 10 & 01 & 02 & 0111 & 3 \\
\hline 11 & 01 & 02 & 0112 & 3 \\
\hline
\end{tabular}

The discriminant rules expressed in Table 4 are stored as a database table as shown in Table 5. The environmental categories are numbered sequentially from 1 to 11 , and construction methods are numbered sequentially from 1 to 4 . Risk grade is expressed from 0 to 3 , where 0 represents special risk.

\section{Risk identification framework and data requirements based on BIM}

\subsection{Framework for environmental risk automatic identification and classification}

In the past, environmental risk identification methods at the design stage were backward, resulting in the methods being inefficient. The environmental object data was obtained from the environmental survey data to determine the importance of an environmental object, and the proximity relationship was determined based on the general plane, line plan/profile view, and the design drawings of the environmental facilities. Finally, the risk level was determined and the technical measures to be implemented were formulated according to the risk analysis diagram of the working conditions.
However, the analysis of key information also involved working backwards, relying on the designers' understanding of the environmental survey data and their spatial imagination of the relative spatial relationships. The process for obtaining this information was complicated and difficult to perform, and there was a risk of misjudging the spatial relationship, thus limiting the efficiency of environmental risk rating.

As shown in Figure 9, this paper proposes a framework for the automatic identification and classification of environmental risks based on the BIM model and discriminant rule base. First, create environmental models and environmental risk discriminant models containing information such as coordinates, numbers, and codes. Then, analyze the collision based on BIM-GIS platform to automatically judge the closeness and the applicable working conditions. Furthermore, generate the environmental risk list after automatically discriminating the risk grade based on discriminant rule base. Carry out special design for environmental risk to specify monitoring and risk inspection requirements during the construction. Finally, integrate the models, monitoring date, and inspection data in the BIM-GIS based platform to manage the environmental risk during construction.

\subsection{Content and requirements for modeling}

The survey unit should submit both the environmental survey data (with a range of 50 to 100 meters along the line) and models such as those for subways, railway lines, bridge construction, civil housing, and municipal pipelines. Designers should pay attention to the following issues when creating environmental models:

- The name of the model should be consistent with the survey data;

- The model should contain correct city rectangular coordinates;

- The environment type number should be entered according to Table 3;

- When a pipeline consists of multiple segments, the segments should be given the same name of number; 


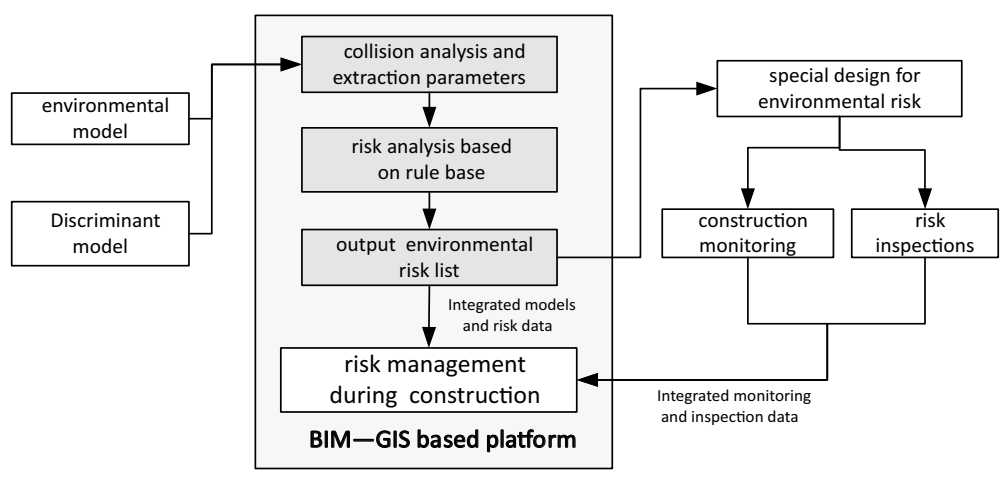

Figure 9. Framework for environmental risk automatic identification and classification

- The model should include information such as structural form, construction year, property rights unit, and pipeline medium to facilitate risk management during the construction phase.

Designers should build environmental risk discriminant models according to the design plan and risk grading diagram, and pay attention to the following issues:

- The model should contain correct city rectangular coordinates;

- The model should contain construction method codes;

- The model should contain the area numbers shown in Figures 5-8;

- Each partition of the discriminant model should be created independently.

As described above, the partitioning rules shown in Figures 5-8 are similar. Therefore, parametric modeling methods should be used when creating discriminant models to cope with changes in the construction plan. When the construction method changes or line position adjustment occurs, a new discriminant model can be quickly generated to improve efficiency. Figure 10 shows the discriminant model of a shield tunnel crossing the foundation of a viaduct.

\subsection{Algorithm for automatically discriminating the risk grade}

The proposed model could accurately reflect the spatial relationship between the proposed project and the surrounding environmental facilities, as well as provide detailed information about the surrounding environment facilities and subway construction data.

Thus, combined with the risk discriminant rule base, the BIM platform could be used to accurately and efficiently determine the environmental risks caused by subway construction. The BIM platform needed to have spatial analysis capabilities and secondary development conditions. Figure 11 illustrates the algorithm principle with five steps:

- The first step involved integrating the model. The BIM platform, with its model data parsing, integration, and analysis capabilities, was used to integrate the environmental models ' $\mathrm{H} j$ ' and the discriminant

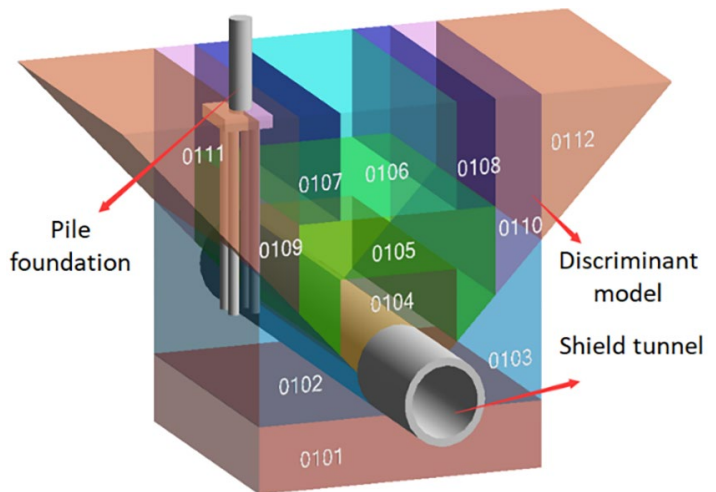

Figure 10. Shield tunnel crossing the foundation of a viaduct

model ' $P i$. The component ID, name of the environmental facilities, environment type number ' $j$ ', construction type number ' $i$, and area number are stored in the database.

- The second step was to analyze the collision. The BIM platform was used to analyze the collision between all of the environmental and discriminant models, and all of the information related to the collision between environmental model ' $H j$ ' with the discriminant model ' $P i$ ' was recorded. The information included the environmental type number ' $j$ ', the construction method number ' $i$ ', a total of ' $m$ ' groups of area number and the coordinates of the collision location. Figure 9 indicates that the bridge model " $\mathrm{H} 2$ " collided with three areas of the shield construction discrimination model ' $P 1$ ', namely, 0102, 0109, and 0111.

- The third step was to determine the discrimination rules. The discrimination rule $F(i, j)$ was automatically selected based on the construction method number ' $i$ ' and the environment type number ' $j$ '. The content corresponding to the discrimination rule $F(1,2)$ is shown in Figure 9 and Table 5.

- The fourth step was to analyze the risk grade. According to the discriminant rule $F(i, j)$, the ' $m$ ' partition codes that were obtained after the collision analysis were traversed, and the risk level corresponding to the code was determined and recorded, eventually forming a set $S(i, j)$. According to Table 5 , the corresponding set of Figure 9 is $S(1,2)=\{1,2,3\}$. 


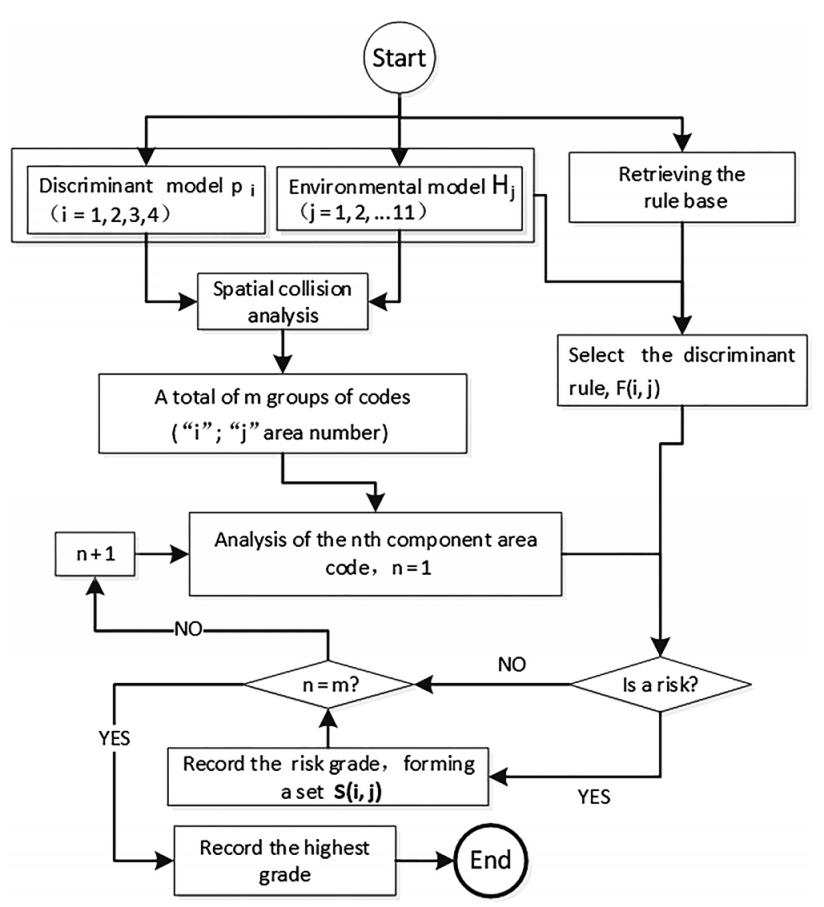

Figure 11. Algorithm environmental risk classification

- The fifth step was to determine the final risk grade. The highest level was determined from the set $S(i, j)$ and the result was output. As shown in Figure 9, the construction of the shield tunnel crossing the bridge foundation incurred a grade 1 risk.

\subsection{Development requirements for the BIM platform}

The model data for the subway had various formats and a large amount of data was generated. A BIM-based platform was needed in order to integrate the surrounding environmental facilities with the rail transit model to achieve the automatic identification of construction-related environmental risks. A platform combining BIM and 3D GIS technology could satisfy the needs of risk management using BIM model as the data carrier and 3D GIS as a data integration, analysis, and display tool. The BIM platform development had to focus on resolving a number of issues.

First, the BIM platform development had to be compatible with common data formats such as 3Dmax, Revit, Bentley, and it had to be able to parse all data, including the component ID, which was the unique identifier of the model in the software.

Second, it had to have a larger data-carrying capacity. A subway line is usually tens of kilometers long. The model had a large amount of data.

Third, it had to have a spatial analysis function or the ability to parse an external collision report. It was necessary to optimize the collision detection algorithm to ensure the accuracy and efficiency of the environmental risk identification. A designer could also use software such as Navisworks, a software program with a collision analysis function, for collision analysis. The designer could then load the collision report into the BIM platform for risk identification.

Fourth, the automatic discrimination algorithm could be realized through secondary development. The risk level was analyzed according to the collision result, and the environmental risk information was extracted and recorded.

Fifth, the BIM platform development had to be able to generate an environmental risk list and navigate to the model in three-dimensional space. The risk list had to include information such as the environmental name, risk level, and construction method.

Sixth, the BIM platform architecture had to account for the management needs of risk control during the construction phase and further explore the value of the model (Zhou \& Ding, 2004). For example, three-dimensional risk management could be implemented based on the construction progress and monitoring data.

\section{Case study}

\subsection{Project overview}

Currently, Beijing Subway Line 19 is an underground line that crosses the central city. The total length of the line is $22.4 \mathrm{~km}$. The Subway Line passes through a large number of municipal pipelines, buildings, and municipal bridges, causing many construction environmental risks. Figure 12 shows the spatial relationship between the tunnel and the crossed bridge. The shield tunnels from Jishuitan Station to North Taipingzhuang Station, with 2080 meters in total length, were selected for example application.

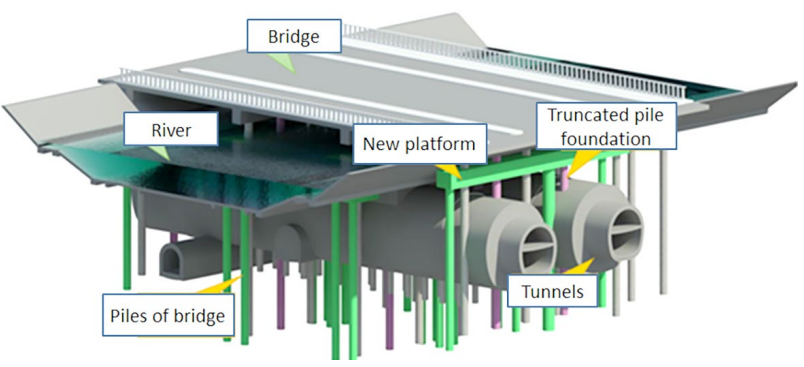

Figure 12. Subway Line 19 crossing rivers and bridges

\subsection{Build models}

The software program 3Dmax was used to build the models of the aboveground buildings, roads, and greening in order to ensure the authenticity of the visual effect. Revit was used to build the models of the building foundations, bridges, rivers, existing rail transit structures, and pipeline. According to the route design scheme and the zoning rules shown in Figure 5, Revit was used to create risk discrimination models for a shield tunnel. All of the models used the city construction Cartesian coordinate system and elevation for Beijing.

The environment name, environment type number, and other basic information were entered in all the component properties of the environmental model. The corresponding area number, construction method number, and 
other basic information were entered in the discriminant models. Figure 13 shows the model creation method and information requirements. The above information and corresponding component ID, unique identification of components in BIM software, will be parsed by the BIM platform and stored in the model database.

\subsection{Collision analysis}

Navisworks was used to detect the collision between the environmental model and the discriminant model. The main data was extracted from the collision report shown in Figure 14, including the ID of the two components that collided and the $\mathrm{X}, \mathrm{Y}$, and $\mathrm{Z}$ coordinates of the collision point.

\subsection{Development of a BIM platform}

The Beijing Subway Line 19, as a BIM demonstration application project in Beijing, has developed a BIM-GIS platform with multi-source data integration capabilities for progress, quality, and safety management. The platform adopts the "Citymaker Server V7.0" invented by Gvitech Technologies as the 3D GIS engine, which has a proprietary data format FDB (feature database). FDB supports the management of hierarchical, vector, and threedimensional symbol data to realize object-oriented data organization and management. The engine also provides a data export tool that can convert BIM data into FDB using software such as Revit, Bentley, and 3Dmax. Figure 15 shows the multivariate model data integrated in the BIM platform. All the information contained in the model is parsed and stored in the database.

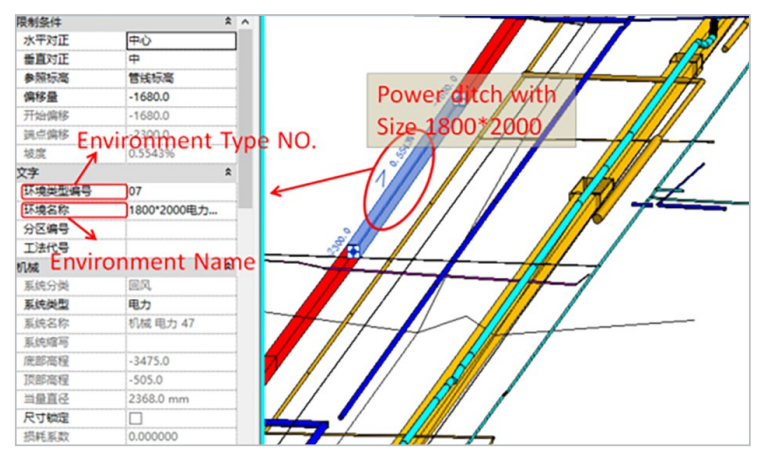

The development of the risk automatic discriminant subsystem was supplemented and the discriminant rule base was embedded. The subsystem included such functions as importing collision reports and background analysis, as well as generating and exporting risk lists. The method helps to obtain relevant parameters by querying the component ID in the collision report shown in Figure 14 and get the risk grade according to the discriminant rules. Moreover, it can locate the collision point in the BIM platform according to the coordinates shown in Figure 15.

\subsection{Result analysis}

As shown in Table 6, the first line is the number of risks and time consumed by traditional method. This method mainly relies on the analysis of two-dimensional data. The second line is the number of risks and time consumed by BIM-based automatic environmental risk identification method automatic.

Using the BIM-based environmental risk identification method, we successfully identified all 38 environmental risk projects caused by the construction of the shield tunnels. The designer spent a total of about three man-hours completing all three steps, including creating a discriminant model, analyzing collisions, and automatically judging the risk level.

Since time consumed by traditional method is related to personal proficiency, the theoretical time required for similar projects is used in the table. This time is obtained through interviews. According to the results of interviews with five engineers with five years of experience with special structural design related to risk, the identification

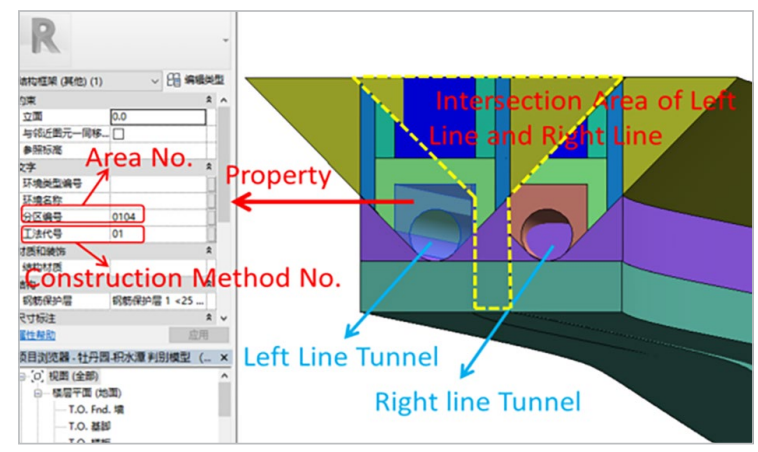

Figure 13. Discriminant models and pipeline models created using Revit

\begin{tabular}{|c|c|c|c|}
\hline $\begin{array}{c}\text { N0. of } \\
\text { Collision }\end{array}$ & Coordinates of Collision Point & ID of Object 1 & ID of Object 2 \\
\hline 1 & $x: 501122.186, y: 310669,828, z: 28.067$ & Element ID: 394727 & FlementID: 367058 \\
\hline 2 & $x: 501227.332 、 y: 309118.881, z: 11.231$ & Pler & ElementID: 394612 \\
\hline 3 & $x: 501231.101 、 y: 309104.251 、 z: 18.713$ & ElementID: 367058 & ElementiD: 394646 \\
\hline 4 & $x: 501226.067 、 y: 309123.789 、 z: 35.636$ & ElementID: 367058 & ElementID: 393011 \\
\hline 5 & $x: 501233.267 、 y: 309095.846 、 z: 26.890$ & ElementID: 367058 & ElementID: 394664 \\
\hline 6 & $x: 501108.305 、 y: 311169.305 、 z: 36.340$ & ElementID: 393277 & ElementID: 230515 \\
\hline 7 & $x: 501232.956 、 y: 309097.052 、 z: 30.086$ & ElementID: 367058 & ElementID: 394673 \\
\hline 8 & $x: 501105.417 、 y: 311168.362 、 z: 36.340$ & ElementID: 394781 & ElementID: 230515 \\
\hline 9 & $x: 501120.202 、 y: 310676.944 、 z: 36.798$ & ElementID: 394727 & ElementID: 341459 \\
\hline 10 & $x: 501131.365 、 y: 310674.305 、 z: 18.580$ & ElementID: 394709 & ElementID: 367058 \\
\hline
\end{tabular}

Figure 14. Part of the generated collision report

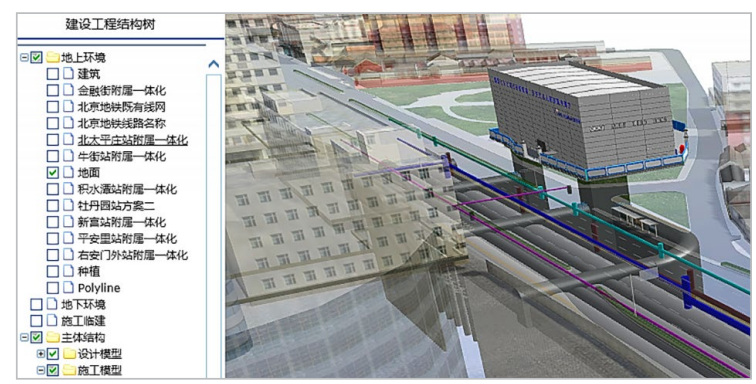

Figure 15. Environmental model integrated into BIM platform 
Table 6. Comparison of the environmental risk identification results

\begin{tabular}{|l|c|c|c|c|c|}
\hline \multirow{2}{*}{ Identification and classification method } & \multicolumn{3}{|c|}{ Number of environmental risks identified } & \multirow{2}{*}{ Time cost (h) } \\
\cline { 2 - 5 } & Special grade & Grade 1 & Grade 2 & Grade 3 & \\
\hline Traditional method & - & 11 & 32 & 62 & 12 \\
\hline Automatic method based on BIM & - & 11 & 32 & 62 & 2 \\
\hline
\end{tabular}

of one environmental risk required about $10 \mathrm{~min}$ on average, and the pipeline took about $5 \mathrm{~min}$, from the acquisition of two-dimensional data to the identification of all of the environmental risk projects. Moreover, when the construction method in the design plan needed to be adjusted, the environmental risk needed to be re-identified, which increased the workload by about $50 \%$. However, the reality was that from the preliminary design to the construction drawing design, the route and the construction method were more likely to change.

With the premise that the survey unit submitted the environmental model as required, BIM-based environmental risk automatic identification and classification saved $83 \%$ of the time spent accurately analyzing. It was proven that the new method greatly improved the efficiency of risk identification. More importantly, subway projects in many cities such as Beijing, Chongqing, and Xiamen have incorporated the submitted environmental model into the work contract of the survey units, which will provide favorable conditions for the promotion of this method.

\subsection{Platform function expansion}

A manager can query detailed information about environmental risk engineering through the risk list and locate the environmental risks in a three-dimensional scene. The platform judges and reminds the passing status of environmental risks according to progress data, and the platform guides managers to focus on the management of the environmental risks during construction.

The interface with the existing risk monitoring system was developed in order to establish the relationship between monitoring points and environmental objects. Managers can view the monitoring and pre-alarm data corresponding to each environmental risk during the construction phase to identify the safety status of environmental risks and support risk management decisions. Figures 16-18 show the risk engineering positioning and monitoring data viewing in the platform.

\section{Summary and conclusions}

This paper introduces the development of a subway engineering safety risk management system in China. A BIMbased automatic identification and grading framework for environmental risks was proposed in order to improve the efficiency of the special design of security risks and achieve the transmission of risk design information throughout the construction process. In this study, the method provided a reference for the safety risk management technol-

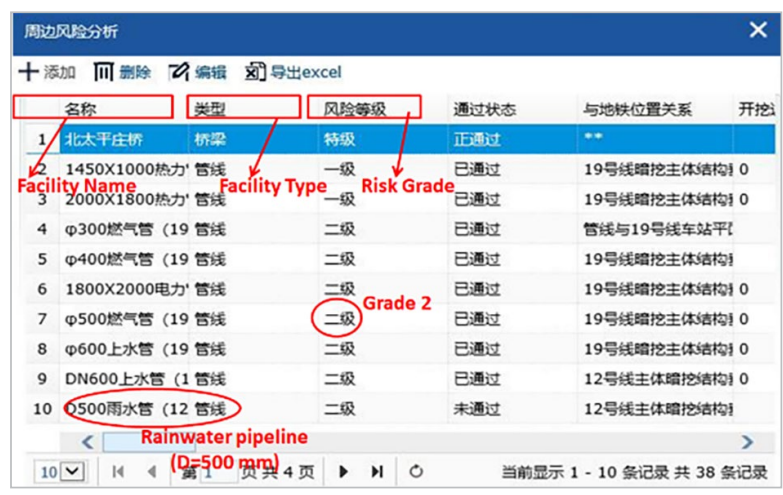

Figure 16. Environmental risk engineering list

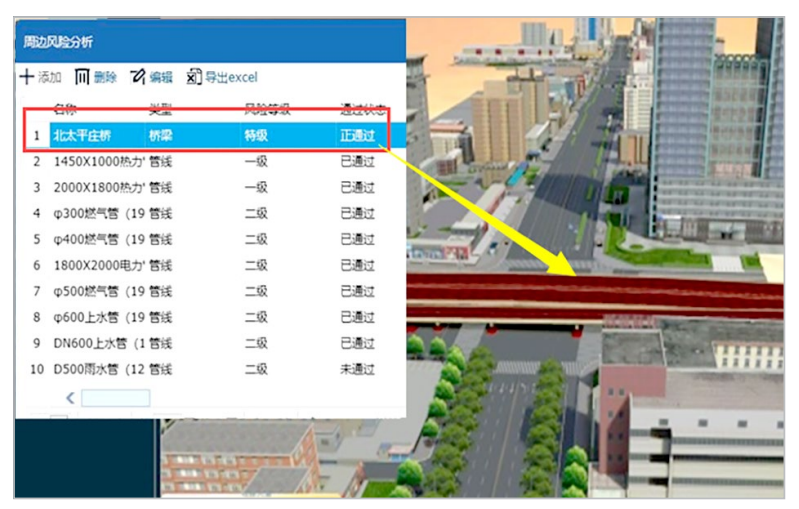

Figure 17. Position risk engineering and view of the monitoring data

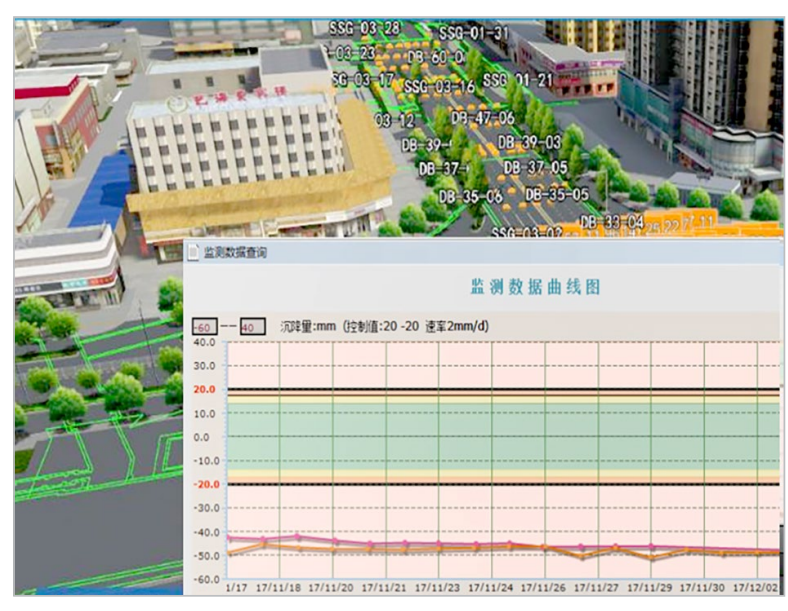

Figure 18. Generated monitoring data time history curve

ogy system in China's subway projects. This method can also be applied to projects, such as underground pipe gallery, power tunnel, and foundation pit, after optimizing the classification rules. The automatic identification and classification of environmental risks involved three steps. 
First, a database of discriminant rules was established in order to achieve the digital expression of discriminant standards for environmental risks. Second, environmental models and discriminant models were built, and space collision was analyzed. Third, the algorithm of risk discrimination was embedded in the BIM platform in order to analyze the collision results and obtain a list of environmental risks. The list contained information such as risk name, construction method, and risk level, which was necessary for design delivery.

The result analysis of the case application proved that the new method could greatly improve the designer's safety risk special design work efficiency. BIM-based risk management promotes information exchange between owners as well as design and construction units, and it provides basic data for the dynamic management of security risks based on three-dimensional visuals.

However, the research described in this paper still has some limitations. For example, the research was conducted based on Beijing's risk rating standards with northern characteristics, which could not be directly used in southern areas with poor geological conditions, and some optimization was needed. This method determines the risk level according to the closeness, construction method, and environmental importance; however, it has not yet realized the automatic adjustment of the risk grade based on the geological model. Discriminant models and environmental models needed to be created, while unintelligent modeling methods increased work. Due to the lack of a spatial analysis function for the BIM platform, Navisworks was used for collision analysis in the case application. The addition of intermediate links led to a certain impact on the automation of risk identification. It is worth noting that with the rise of City Information Modeling (CIM) in China, environmental models that contain full-factor information will be an indispensable part of subway engineering. This will provide favorable conditions for the promotion of research results. It will also promote the research results of this paper.

There are still many obstacles to overcome regarding the application and development of BIM technology in the construction industry.

Whether the model creation method is convenient and whether the same model can have value in multiple scenarios is an important factor. Thus, more in-depth research will be carried out in the future. This will involve a further examination of the method, whereby line parameters will be used to intelligently drive the establishment of the partition model to reduce the manual modeling work. The development of a collision detection function for application to a BIM-based platform is required in order to satisfy the needs of spatial analysis and to improve the automation of environmental risk grade discrimination. Further, it will be necessary to optimize the data standard for the model required for construction environment risk identification, combining the needs of schedule, quality, and cost management.

\section{Acknowledgements}

This research was supported by the Beijing Key R\&D Program of China (Z171100000517001). We thank LetPub (www.letpub.com) for its linguistic assistance during the preparation of this manuscript.

\section{Funding}

This work was supported by the $<$ Beijing Key R\&D Program of China> under Grant [Z171100000517001].

\section{Author contributions}

Mingke Zhou, Yuegang Tang and Huai Jin have conceived the study and were responsible for the design and structure of the paper. Xuewen Sang and Bo Zhang were responsible for BIM-based platform development and data analysis. Mingke Zhou wrote drafts of the paper.

\section{Disclosure statement}

Nothing to declare.

\section{References}

Bansal, V. K. (2011). Application of geographic information systems in construction safety planning. International Journal of Project Management, 29(1), 66-77.

https://doi.org/10.1016/j.ijproman.2010.01.007

Beijing Municipal Commission of Housing and Urban-Rural Development. (2014). Code for safety risk assessment of urban rail transit engineering design. http://ghzrzyw.beijing.gov.cn/biaozhunguanli/bz/szjgdjt/202002/P020200220556004092533. pdf

Becerik-Gerber, B., Jazizadeh, F., Li, N., \& Calis, G. (2012). Application areas and data requirements for BIM-enabled facilities management. Journal of Construction Engineering and Management, 138(3), 431-442.

https://doi.org/10.1061/(ASCE)CO.1943-7862.0000433

Chen, L. J., \& Luo, H. (2014). A BIM-based construction quality management model and its applications. Automation in Construction, 46, 64-73.

https://doi.org/10.1016/j.autcon.2014.05.009

Chinese Academy of Engineering. (2018, December 07). Engineering fronts 2018. http://www.cae.cn/cae/html/main/ col1/2018-12/07/20181207171831177603659_1.html

Ding, L., \& Zhou, C. (2013). Development of web-based system for safety risk early warning in urban metro construction. Automation in Construction, 34, 45-55. https://doi.org/10.1016/j.autcon.2012.11.001

Ding, L. Y., Yu, H. L., Li, H., Zhou, C., Wu, X. G., \& Yu, M. H. (2012). Safety risk identification system for metro construction on the basis of construction drawings. Automation in Construction, 27, 120-137. https://doi.org/10.1016/j.autcon.2012.05.010

Ding, L. Y., Zhou, C., Deng, Q. X., Luo, H. B., Ye, X. W., \& Ni, Y. Q. (2013). Real-time safety early warning system for cross passage construction in Yangtze Riverbed Metro Tunnel based on the internet of things. Automation in Construction, 36, 25-37. https://doi.org/10.1016/j.autcon.2013.08.017 
Dong, S., Li, H., \& Yin, Q. (2018). Building information modeling in combination with real time location systems and sensors for safety performance enhancement. Safety Science, 102, 226-237. https://doi.org/10.1016/j.ssci.2017.10.011

Dossick, C. S., \& Neff, G. (2011). Messy talk and clean technology: communication, problem-solving and collaboration using Building Information Modelling. Engineering Project Organization Journal, 1(2), 83-93.

https://doi.org/10.1080/21573727.2011.569929

Fernández-Rodríguez, S., Cortés-Pérez, J. P., Muriel, P. P., Tormo-Molina, R., \& Maya-Manzano, J. M. (2018). Environmental impact assessment of pinaceae airborne pollen and green infrastructure using BIM. Automation in Construction, 96, 494-507. https://doi.org/10.1016/j.autcon.2018.10.011

Hossain, M. A., Abbott, E. L. S., Chua, D. K. H., Qui, N. T., \& Goh, Y. M. (2018). Design-for-safety knowledge library for BIMintegrated safety risk reviews. Automation in Construction, 94, 290-302. https://doi.org/10.1016/j.autcon.2018.07.010

Isaac, S., Curreli, M., \& Stoliar, Y. (2017). Work packaging with BIM. Automation in Construction, 83, 121-133. https://doi.org/10.1016/j.autcon.2017.08.030

Jin, H., Liu, Y. Q., \& Zhong, Q. R. (2008). Current status and prospects of metro safety risk management in China. Journal Geotechnical Investigation \& Surveying, 2, 216-220.

Jin, H., Huang, F. L., \& Liu, Y. Q. (2011). The geological environments safe problem of metro construction. Construction Technology, 40(10), 27-29.

Jin, R., Hancock, C. M., \& Tang, L. (2017). BIM investment, returns, and risks in China's AEC industries. Journal of Construction Engineering and Management, 143(12), 04017089. https://doi.org/10.1061/(ASCE)CO.1943-7862.0001408

Kim, K., Cho, Y., \& Kim, K. (2018). BIM-driven automated decision support system for safety planning of temporary structures. Journal of Construction Engineering and Management, 144(8), 04018072.

https://doi.org/10.1061/(ASCE)CO.1943-7862.0001519

Li, M., Yu, H., Jin, H., \& Liu, P. (2018a). Methodologies of safety risk control for China's metro construction based on BIM. Safety Science, 110 (Part A), 418-426.

https://doi.org/10.1016/j.ssci.2018.03.026

Li, M., Yu, H., \& Liu, P. (2018b). An automated safety risk recognition mechanism for underground construction at the preconstruction stage based on BIM. Automation in Construction, 91, 284-292. https://doi.org/10.1016/j.autcon.2018.03.013

Lu, Y., Gong, P., Tang, Y., Sun, S., \& Li, Q. (2021). BIM-integrated construction safety risk assessment at the design stage of building projects. Automation in Construction, 124, 103553. https://doi.org/10.1016/j.autcon.2021.103553

Luo, F. R. (2009). Study on innovation of safety management of Beijing subway construction. Urban Rapid Rail Transit, 22(2), 9-12.

Luo, H., \& Gong, P. (2015). A BIM-based code compliance checking process of deep foundation construction plans. Journal of Intelligent \& Robotic Systems, 79, 549-576.

https://doi.org/10.1007/s10846-014-0120-Z

Luo, J.-J., Zhang, D.-L., Wang, M.-S., \& Zhang, C.-P. (2007). Security risk management of neighboring buildings during metro construction. Rock and Soil Mechanics, 7, 196-201.

Ma, Z. L., \& Mao, N. (2015). An algorithm for automatic generation of construction quality inspection points based on BIM. Journal of Tongji University (Natural Science), 44(5), 725-729.

Malekitabar, H., Ardeshir, A., Sebt, M. H., \& Stouffs, R. (2016). Construction safety risk drivers: A BIM approach. Safety Science, 82, 445-455. https://doi.org/10.1016/j.ssci.2015.11.002
Park, J., Cai, H., Dunston, P. S., \& Ghasemkhani, H. (2017). Database-supported and web-based visualization for daily $4 \mathrm{D}$ BIM. Journal of Construction Engineering and Management, 143(10), 04017078.

https://doi.org/10.1061/(ASCE)CO.1943-7862.0001392

Rahimian, F. P., Seyedzadeh, S., Oliver, S., Rodriguez, S., \& Dawood, N. (2019). On-demand monitoring of construction projects through a game-like hybrid application of BIM and machine learning. Automation in Construction, 110, 103012. https://doi.org/10.1016/j.autcon.2019.103012

$\mathrm{Qu}, \mathrm{H}$. H. (2017). Application of BIM in safety management. Construction Technology, 46(S1), 533-536.

Sacks, R., Koskela, L., Dave, B. A., \& Owen, R. (2010). Interaction of lean and building information modeling in construction. Journal of Construction Engineering and Management, 136(9), 968-980. https://doi.org/10.1061/(ASCE)CO.1943-7862.0000203

Santos, R., Costa, A. A., Silvestre, J. D., \& Pyl, L. (2019). Informetric analysis and review of literature on the role of BIM in sustainable construction. Automation in Construction, 103, 221-234. https://doi.org/10.1016/j.autcon.2019.02.022

Sloot, R. N. F., Heutink, A., \& Voordijk, J. T. (2019). Assessing usefulness of $4 \mathrm{D}$ BIM tools in risk mitigation strategies. $\mathrm{Au}$ tomation in Construction, 106, 102881.

https://doi.org/10.1016/j.autcon.2019.102881

Shim, C. S., Lee, K. M., Kang, L. S., Hwang, J., \& Kim, Y. (2012). Three-dimensional information model-based bridge engineering in Korea. Structural Engineering International, 22(1), 8-13. https://doi.org/10.2749/101686612x13216060212834

Shen, Y.-s., Wang, P., Li, M.-p., \& Mei, Q.-w. (2019). Application of subway foundation pit engineering risk assessment: a case study of Qingdao rock area, China. KSCE Journal of Civil Engineering, 23(11), 4621-4630.

https://doi.org/10.1007/s12205-019-1854-8

Song, Z., Shi, G., Wang, J., Wei, H., Wang, T., \& Zhou, G. (2019). Research on management and application of tunnel engineering based on BIM technology. Journal of Civil Engineering and Management, 25(8), 785-797. https://doi.org/10.3846/jcem.2019.11056

Tam, C. M., Zeng, S. X., \& Deng, Z. M. (2004). Identifying elements of poor construction safety management in China. Safety Science, 42, 569-586.

https://doi.org/10.1016/j.autcon.2014.04.012

Wang, J., Wang, P. F., \& Tan, Y. H. (2009). Study on risk management of subway tunnel engineering during construction process. Chinese Journal of Underground Space and Engineering, 5(2), 385-389.

Wang, H., Pan, Y., \& Luo, X. (2019a). Integration of BIM and GIS in sustainable built environment: A review and bibliometric analysis. Automation in Construction, 103, 41-52. https://doi.org/10.1016/j.autcon.2019.03.005

Wang, M., Deng, Y., Won, J., \& Cheng, J. C. P. (2019b). An integrated underground utility management and decision support based on BIM and GIS. Automation in Construction, 107, 102931. https://doi.org/10.1016/j.autcon.2019.102931

Wu, X. G., Chen, X. Y., \& Ding, L. Y., (2011). Safety risk rank evaluation of adjacent buildings during metro tunneling construction. Construction Technology, 40, 78-80.

Wu, F. B., Jin, H., \& Xu, Y. D. (2012). The risk classification criteria of underground works in metro. Construction Technology, $41,62-74$.

Yang, S. 1., Wang, M. S., \& Zhang, C. P. (2004). Study and implementation of the third party monitoring in construction safety of urban subway. China Safety Science Journal, 14(10), 73-76. 
Tang, Y., Xia, N., \& Lu, Y. (2021). BIM-based safety design for emergency evacuation of metro stations. Automation in Construction, 123, 103511.

https://doi.org/10.1016/j.autcon.2020.103511

Yu, Q. Z., Ding, L. Y., \& Zhou, C. (2014). Analysis of factors influencing safety management for metro construction in China. Accident Analysis \& Prevention, 68, 131-138.

https://doi.org/10.1016/j.aap.2013.07.016

Yu, Q., Li, K., \& Luo, H. B. (2016). A BIM-based dynamic model for site material supply. Procedia Engineering, 164, 526-533. https://doi.org/10.1016/j.proeng.2016.11.654

Zhang, Y., Huang, H. W., \& Hu, Q. F. (2012). Introduction of code for risk management of underground words in metro GB50652-2011. Construction Technology, 41(1), 99-106.

Zhang, L., Wu, X., Ding, L., Skibniewski, M. J., \& Lu, Y. (2016). BIM-based risk identification system in tunnel construction. Journal of Civil Engineering and Management, 22(4), 529-539. https://doi.org/10.3846/13923730.2015.1023348

Zhou, Y., \& Ding, L. Y. (2004). Study of Wuhan rail transit project controlling support system. Journal of Civil Engineering and Management, 21(2), 16-18 (in Chinese).

Zhou, Y., Ding, L. Y, \& Chen, L. J. (2013). Application of 4D visualization technology for safety management in metro construction. Automation in Construction, 34(13), 25-36. https://doi.org/10.1016/j.autcon.2012.10.011

Zhou, Y., Su, W. J., Ding, L., Luo, H., \& Love, P. E. D. (2017). Predicting safety risks in deep foundation pits in subway infrastructure projects: support vector machine approach. Journal of Computing in Civil Engineering, 31(5), 04017052. https://doi.org/10.1061/(ASCE)CP.1943-5487.0000700

Zhou, Y., Li, S., Zhou, C., \& Luo, H. (2019). Intelligent approach based on random forest for safety risk prediction of deep foundation pit in subway stations. Journal of Computing in Civil Engineering, 33(1), 05018004.

https://doi.org/10.1061/(ASCE)CP.1943-5487.0000796

Zou, P. X. W., Zhang, G., \& Wang, J. (2007). Understanding the key risks in construction projects in China. International Journal of Project Management, 25, 601-614. https://doi.org/10.1016/j.ijproman.2007.03.001

Zou, Y., Kiviniemi, A., \& Jones, S. W. (2017). A review of risk management through BIM and BIM-related technologies. Safety Science, 97, 88-98.

https://doi.org/10.1016/j.ssci.2015.12.027 